[Agr. Biol. Chem., Vol. 32, No. 7, p. 810 815, 1968]

\title{
Studies on the Hypertrophic Disease of Cherry (Genus Prunus), So-called "Witch's Broom" Caused by Taphrina wiesneri
}

Part I. On the Metabolites of $T$ wiesneri* $^{*}$

\author{
By Satoshi Fujil, Hiroo Aoki, ${ }^{* *}$ Masahiko Кômoto, Katsura Munakata** \\ and the late Teiichi Tamura \\ The Hyogo University of Agriculture, Sasayama, Hyogo;** Faculty \\ of Agriculture, Nagoya University, Nagoya \\ Received August 26, 1967
}

\begin{abstract}
Metabolites of Taphrina wiesneri (Rath.) Mix. were examined. Brassicasterol, stearic acid, and $p$-hydroxyphenylacetic acid were isolated in crystalline form. $p$-Hydroxybenzoic acid and vanillic acid were identified by paper chromatography and UV measurement. Palmitic acid was identified by gas-chromatography. The fungus produced usually these compounds on any one of four kinds of medium used. p-Hydroxyphenylacetic acid promoted germination of rape seeds at the concentration of $20 \mathrm{ppm}$ in water and showed inhibition at $250 \mathrm{ppm}$.
\end{abstract}

The so-called witch's broom which has been well known as a principal disease of Japanese flowering cherry is caused by Taphrina wiesneri. Hitherto several studies on the substances produced by the fungus have been published. Hattori and Kinoshita ${ }^{\text {I) }}$ reported that the acidic extract of the fungal body of $T$ cerasi contained a substance which inhibits elongation of Avena roots. Hirata ${ }^{21}$ has shown the formation of indole-3-acetic acid by Taphrina sp. cultured in Czapek-Dox's solution containing tryptophan as a nitrogen source. Matsuyama and Misawa ${ }^{3}$ cultured Taphrina sp. in a nutrient solution containing glutamic acid as a nitrogen source, and isolated a physiologically active substance which was later

* The outline of this work was presented at the Annual Meeting of the Agricultural Chemical Society of Japan held at Kyoto in April, 1966.

1) S. Hattori and S. Kinoshita, Bot. Mag. Japan, 54, 58 (1940).

2) S. Hirata, Ann. Phytopath. Soc. Japan, 2324 (1958).

3) N. Matsuyama and Y. Misawa, Tohoku J. Agr. Res., 14, 1 (1963). identified as succinic acid. They ${ }^{4}$ also have reported in vitro formation of auxin from various amino acids by $T$ wiesneri. The purpose of these works were limitted to the isolation of some of physiologically active substances produced by the fungus.

In order to reveal the nature of the disease, we attempted to isolate metabolites which have not been identified. $T$. wiesneri was cultured on four kinds of medium. The metabolities of the fungus were examined and six compounds were identified as brassicasterol, stearic acid, palmitic acid, $p$-hydroxyphenylacetic acid, $p$-hydroxybenzoic acid and vanillic acid.

\section{EXPERIMENTAL AND RESULTS}

\section{Culture}

Taphrina wiesneri (Rath.) Mix.* was cultured on the following media; A) malt extract-agar (with $2 \%$ glucose), B) potato extract-agar, C)

4) N. Matsuyama and Y. Misawa, Tohoku J. Agr.
Res., 17, 37 (1966). Res., 17, 37 (1966).

* Taphrina wiesneri (Rath.) Mix. was kindly supplied by Nagao Kenkyusho. 
Czapek-Dox's solution-agar, and D) modified Czapek-Dox's solution**-agar. Each medium was placed in $100 \mathrm{ml}$ Erlenmeyer flasks, inoculated with suspension of seed fungus and incubated for four weeks at $14 \sim 15^{\circ} \mathrm{C}$.

\section{Fractionation of products}

Fractionation was carried out according to the procedure shown in Chart 1. A large amount of acetone was poured into the culture flasks at the end of culture. Faint pink-colored mycelia were suspended in the acetone by scraping and swirling, and filtered. The filter cake was washed with acetone until the washings was no more colored. The filtrate was combined with the washings and evaporated. The residue was routinely fractionated into three parts-acidic, neutral and basic. The products contained in each fraction are shown in Fig. 1. Production of seven compounds were commonly recognized

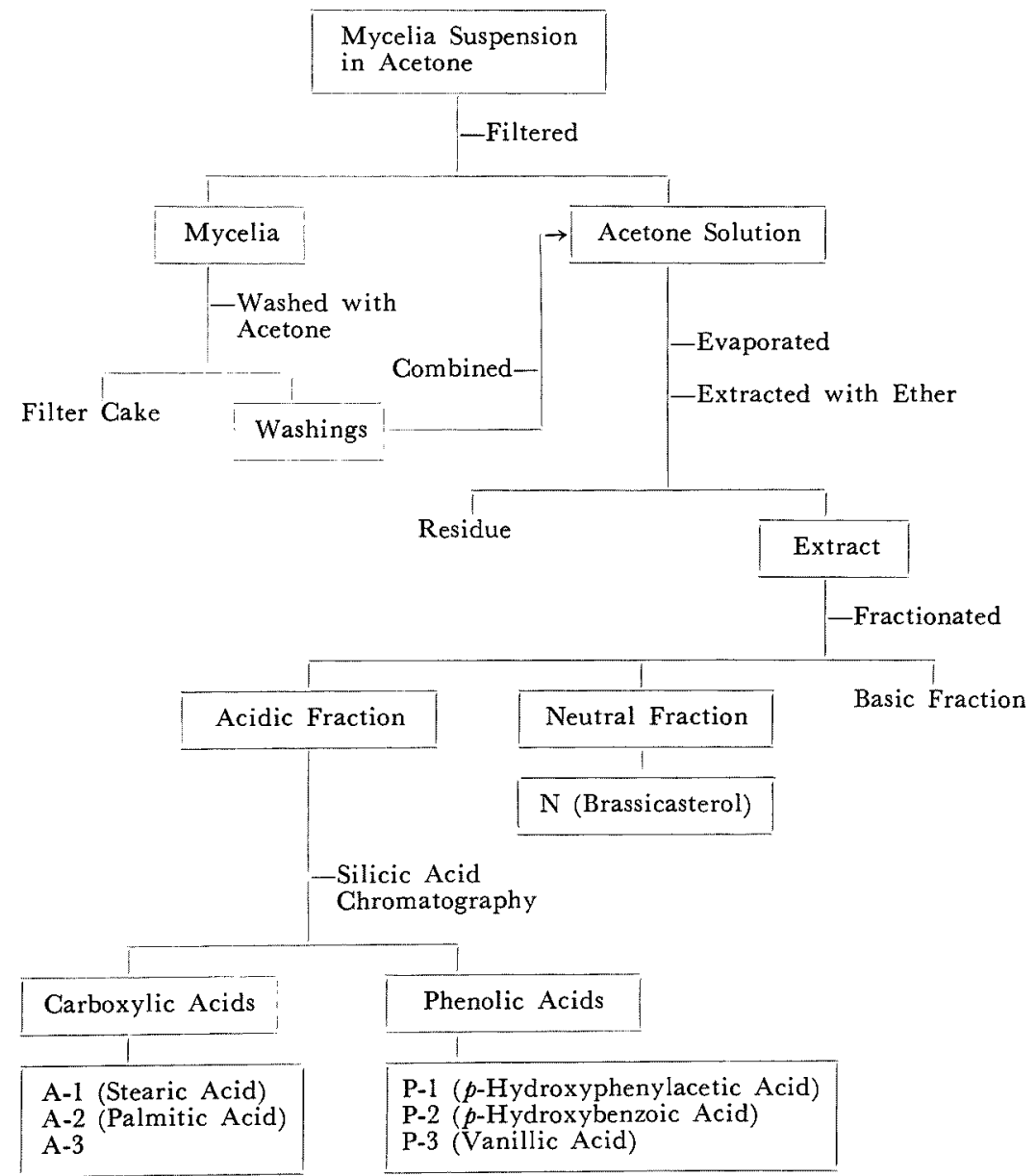

Ghart 1. Fractionation Procedure of Metabolites of T. wiesneri.

** The extract obtained by boiling $100 \mathrm{~g}$ of cherry branches with $300 \mathrm{ml}$ of water for $30 \mathrm{~min}$ was used to make up Czapek-Dox's solution in place of water. 


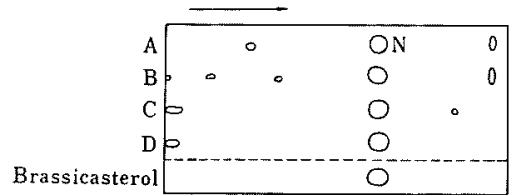

a) Thin-layer chromatogram of neutral fraction solvent: Benzene-MeOH $(8: 2)$ spray reagent: conc. $\mathrm{H}_{2} \mathrm{SO}_{4}$.

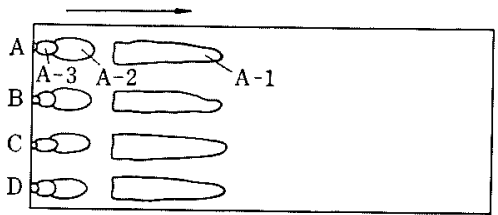

b) Thin-layer chromatogram of acidic fraction solvent: Benzene-MeOH $(9: 1)$ spray reagent: methyl red.

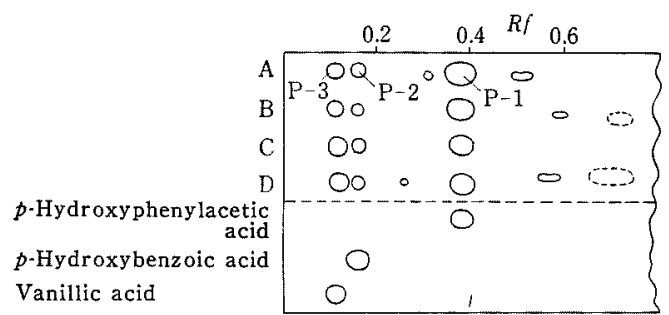

c) Paper chromatogram of acidic fraction solvent: isoPrOH-28\% aq. Ammonia- $\mathrm{H}_{2} \mathrm{O}(8: 1: 1)$ spray reagent: diazotized sulfanilic acid.

A, malt-agar; B, potato-agar; C, Czapek-Dox's solution-agar; D, modified Czapek-Dox's solutionagar.

FIG. 1. Metabolites of $T$. wiesneri Cultured on Various Media.

on the four media. In the acidic extract, six substances were detected chromatographically; three substances $(A-1 \sim 3)$ gave acid reaction to methyl red indicator and the other three $(\mathrm{P}-1 \sim 3)$ were positive to diazotized sulfanilic acid. In the neutral extract a steroidal substance $(\mathrm{N})$ was detected by thinlayer chromatography. The basic fraction was very little. The yields of mycelia and ether-extractable substances are given in Table I. Since the yield was the highest with the medium $\mathrm{A}$, the medium was adopted
TABLE I. YIELdS OF DRIED MYCELIUM OF T. wiesneri AND THE ETHER EXTRACTS OF THE MYCELIUM FROM FOUR MEDIA (per 100 of Erlenmeyer flasks)

$\begin{array}{ccc}\text { Medium } & \text { Dried Mycelium } & \begin{array}{c}\text { Ether Extract } \\ (\mathrm{mg})\end{array} \\ \text { A } & 18.9 & 450 \\ \text { B } & 6.2 & 308 \\ \text { C } & 1.5 & 68 \\ \text { D } & 2.4 & 130\end{array}$

for further preparative experiments.

III. Isolation and indentification of Substrance $\mathbf{N}$ Ether solution of the neutral fraction (Chart 1) was dried over anhydrous sodium sulfate and evaporated. The oily residue $(0.14 \mathrm{~g}$, corresponding to $80 \mathrm{~g}$ of fungal body) was subjected to silicic acid column chromatography using chloroform as a solvent. Fractions containing substance $\mathrm{N}$ were collected and evaporated. The yield of crude crystalline $\mathrm{N}$ was $72 \mathrm{mg}$. Successive recrystallization from methanol, acetone and ethanol gave crystalline colorless plate, $\mathrm{mp} 148^{\circ} \mathrm{C}$. However, contamination was detected by thin-layer chromatography. Substance N gave positive reaction to either Lieberman-Burchard test or Salkovski test and showed no specific absorption in UV region. $[\alpha]_{D}{ }^{22}=-60.2^{\circ}$ ( $c=0.4$, chloroform). Sixty milligrams of slightly impure $\mathrm{N}$ was acetylated with acetic anhydride and pyridine at room temperature. The reaction mixture was allowed to stand over night, and then water was added to the mixture. Resulting crystalline precipitates were filtered. Repeated recrystallizations from methanol gave $11 \mathrm{mg}$ of the acetate, $\mathrm{mp} 152 \sim 153^{\circ} \mathrm{C},[\alpha]_{D}{ }^{22}=-64.0^{\circ} \quad(c=0.3$, chloroform). The acetylated $\mathrm{N}(20 \mathrm{mg})$ was converted into the tetrabromide according to the Fieser's method. ${ }^{51}$ Recrystallization from a chloroform-methanol mixture gave $28 \mathrm{mg}$ of the tetrabromide, $\operatorname{mp} 203 \sim 204^{\circ} \mathrm{C}$. The tetrabromide was subjected to debromination with

5) L.F. Fieser, "Experiments in Organic Chem. istry," Maruzen, 1961 p. 68. 
zink dust-acetic acid. Recrystallization from methanol gave thin-layer-chromatographically pure coloress crystals, $\operatorname{mp} 152^{\circ} \mathrm{C},[\alpha]_{D}{ }^{22}=$ $-64.1^{\circ}$ ( $c=0.3$, chloroform), molecular weight 440 (by Mass spectroscopy). Anal. Found: C, 76.08; $\mathrm{H}, 9.90$. Calcd. for $\mathrm{C}_{28} \mathrm{H}_{46} \mathrm{O}_{2}:$ C, $76.01 ; \mathrm{H}, 10.05 \%$. The above physical constants were in good agreement with those ${ }^{6}$ of brassicasterol ${ }^{*}$ and its derivatives. ${ }^{* *}$ The sterol was also isolated from mycelia of $T$ wiesneri grown on the other three media.

IV. Isolation and identification of substance A-1

Ether solution of the acidic fraction (Chart 1) was dried over anhydrous sodium sulfate and concentrated. The oily residue $(260 \mathrm{mg})$ was subjected to silicic acid column chromatography with a chloroform-methanol $(3 \%)$ mixture. With $250 \mathrm{ml}$ of the solvent substances A-1, -2 and -3 (Chart 1) were eluted, but substaces $\mathrm{P}-1,-2$ and -3 , and colored substances remained on the column. The fractions containing A-1 were collected, evaporated and rechromatographed with methanol-saturated $n$-hexane. The fractions containing A-1 were collected and concentrated. The resulting crystalline mass $(148 \mathrm{mg}$ ) was recrystallized from methanol to give colorless prisms which melted at $65 \sim 67^{\circ} \mathrm{C}$. A small amount of contamination was detected by thin-layer chromatography. Fifty milligrams of substance A-1 was methylated with diazomethane, and column-chromatographed on silicic acid with benzene. The main fractions containing methylated A-1 were collected and evaporated. Resulting methylated A-1 melted at $37^{\circ} \mathrm{C}$. Molecular weight 298 (by Mass spectroscopy). Thirty milligrams of methylated A-1 was refluxed with $5 \%$ potassium hydroxide solution. The reaction mixture was acidified and extracted with ether. The

6) Y. Toyama, T. Takagi and T. Tanaka, J. Chem. Soc. Japan, 26, 154 (1953); E. Fernhorz and H. E. Stavely, J. Am. Chem. Soc., 62, 428 (1940).

* Authentic brassicasterol was kindly supplied by Prof. Taro Matsumoto, Nihon University.

** Authentic brassicasteryl acetate was kindly given by Prof. Yoshiyuki Toyama, The Toyo University. extract was dried over anhydrous sodium sulfate and concentrated. Recrystallization of the resulting mass $(22 \mathrm{mg}$ ) from methanol gave colorless prisms, $\mathrm{mp} 65 \sim 67^{\circ} \mathrm{C}$, molecular weight 284 (by Mass spectroscopy). Anal. Found: C, 75.80; H, 12.82. Calcd. for $\mathrm{C}_{18} \mathrm{H}_{36} \mathrm{O}_{2}: \quad \mathrm{C}, 75.99 ; \mathrm{H}, 12.76 \%$. The physical constants, the IR and the Mass spectra, and the chromatographic behaviors of substance A-1 were identical with those of stearic acid. $p$-Bromophenacyl ester of A-1 was melted at $88 \sim 90^{\circ} \mathrm{C}$.

V. Identification of substance $A-1$ and $A-2$ by gas chromatography

Fractions containing substances A-1, -2 and -3 obtained by silicic acid column chromatography in the experiment IV, were combined, evaporated to thick sirup and methylated

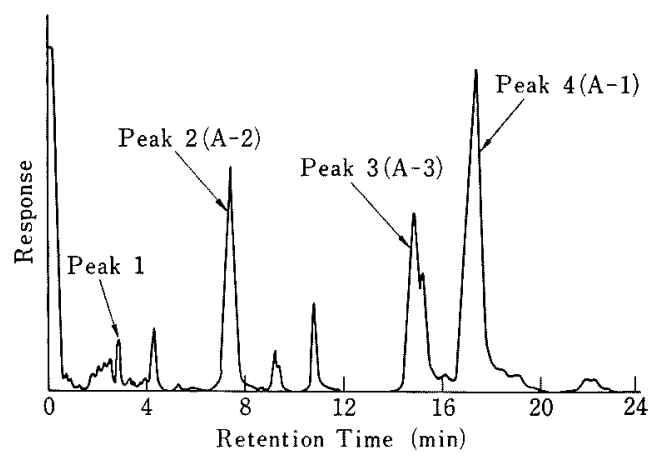

a) Sample

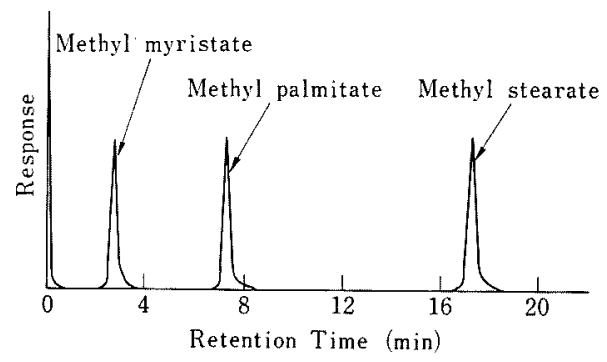

b) Authentic Preparations

FIG. 2. Gas Chromatograms of Methylation Mixture Containing $\mathrm{A}-1,-2$ and -3 .

Flow rate of $\mathrm{N}_{2}$ gas, $2.5 \mathrm{~kg} / \mathrm{cm}^{2}$; Oven temperature, $200^{\circ} \mathrm{C} ; 15 \mathrm{~m}$ of capillary column of apiezon grease $\mathrm{L}$. 
with diazomethane. The product was analysed with a Hitachi "K-53 Model" gas chromatograph equipped with a $15 \mathrm{~m}$ capillary column of apiezon grease L. Operating temperature was $200^{\circ} \mathrm{C}$ with a nitrogen gas flow of $2.5 \mathrm{~kg}$ per $\mathrm{cm}^{2}$. The result obtained is shown in Fig. 2-a. Of big three peaks, peak $2(\mathrm{~A}-2)$ and peak 4 (A-1) were identified as those of methyl palmitate and methyl stearate, respectively. Methylated A-3 represented peak 3. The retention time of peak 1 was the same as that of methyl myristate.

VI. Isolation and identification of phenolic acids

The substances which remained on the silicic acid column in the experiment IV were eluted with methanol. A small amount of active carbon was added to the eluate, stirred for an hour and separated from the solvent. The carbon was stirred in methanol-28\% aq. ammonia (95:5) for three hours and filtered off. The filtrate was concentrated under reduced pressure. The resulting sirup was paper-chromatographed with isopropanol-28\% aq. ammonia-water $(8: 1: 1)$. Areas corresponding to phenolic acids $(\mathrm{P}-1 \sim 3)$ were detected by diazotized sulfanilic acid. The areas were cut out and eluted with water. After decolorizing with active carbon, the eluates were concentrated under reduced pressure. The yields per $800 \mathrm{~g}$ of fungal body were as follows: P-1, $20 \mathrm{mg}$; P-2 a small quantity; and P-3, $5 \mathrm{mg}$. These products were subjected to paper chromatography using Tôyô Roshi No. 50 filter papers in ascending technique. As shown in Table II three solvents and three spray reagents were used. UV spectra were measured with a Hitachi "EPS-2 Model" recording spectrophotometer. Each phenolic acid was dissolved in absolute methanol or methanol containing a drop of $1 \%$ methanolic aluminum chloride solution. ${ }^{7}$ The results of paper chromatography and UV absorption measurements are shown in Table II. Recrystallization of substance P-1 from ethanol gave colorless needles which melted at $145 \sim 147^{\circ} \mathrm{C}$. The IR spectrum of P-1 showed the same pattern as that of authentic $p$-hydroxyphenylacetic acid. P-1, -2 and -3 were identified with $p$ hydroxyphenylacetic acid, $p$-hydroxybenzoic acid and vanillic acid, respectively.

\section{DISCUSSION}

Although some reports concerning microbial production of sterols have been published, the production of brassicasterol was described only by Wirth et $a l^{81}$ who isolated it from a culture broth of Trichophyton rubrum strains.

Table II. Chromatographic Behavior and UV absorption of Three Phenolic acids Solvents: A) isoPrOH-28\% aq. Ammonia- $\mathrm{H}_{2} \mathrm{O}(8: 1: 1)$; B) $20 \%$ aq. $\mathrm{KCl}$; C) Benzene-Propionic Acid- $\mathrm{H}_{2} \mathrm{O}(2: 1: 1)$.

Spray Reagent: A) Diazotized Sulfanilic Acid; B) Diazotized $p$-Nitroaniline; C) Gibbs's Reagent.

Compound

P-1
$p$-Hydroxyphenylacetic
$\quad$ acid
P-2
$p$-Hydroxybenzoic acid
P-3
Vanillic acid

7) Y. Nakagawa, M.R. Shetler and S.H. Wender, Anal. Biochem., 7, 374 (1964).

\begin{tabular}{|c|c|c|c|c|c|c|c|}
\hline \multicolumn{3}{|c|}{$R f$ value } & \multicolumn{2}{|r|}{ Color Reaction } & \multicolumn{3}{|c|}{ UV Absorption $\lambda_{\max }(\mathrm{m} \mu)$} \\
\hline A & B & $\mathrm{C}$ & A & B & $\mathrm{C}$ & in $\mathrm{MeOH}$ & with $\mathrm{AlCl}_{3}$ \\
\hline 0.38 & 0.86 & 0.50 & pink & bluish purple & none & 226,278 & 226,276 \\
\hline 0.38 & 0.87 & 0.50 & pink & bluish pu & none & 226 & 226,276 \\
\hline 0.1 & 0.59 & 0.54 & yello & red & one & 254 & 262 \\
\hline 0.16 & 0.60 & 0.54 & yellow & red & none & 254 & 262 \\
\hline 0.11 & 0.40 & 0.84 & orange & dark pury & blue & 258,290 & 265,296 \\
\hline 0.12 & 0.40 & 0.84 & orange & dark purple & blue & 258,290 & 265,296 \\
\hline
\end{tabular}

8) J. C. Wirth, T. Beesley and W. Miller, J. 
Furthermore, Wirth and Anald, ${ }^{9 \prime}$ and Audette et al. $^{101}$ pointed out that Trichophyton $\mathrm{sp.}$ produced higher fatty acids including stearic acid and palmitic acid. Trichophyton rubrum resembles Taphrina wiesneri only in their parasitic nature; the former is parasite to an animal and the latter to a plant. It is interesting in chemotaxonomy that these two species of fungi produce the same compounds.

The three phenolic acids above mentioned are also produced by several fungi and distributed widely in the plant kingdom.

Some biological tests were carried out for the products. Brassicasterol, stearic acid, $p$ hydroxybenzoic acid and vanillic acid showed no activity in the lamina joint test, ${ }^{111}$ and

9) J. C. Wirth and S. R. Anald, Can. J. Microbiol., 10, 23 (1964).

10) R.C.S. Audette, R. M. Baxter and G. C. Walker, ibid., 7, 282 (1961).

11) E. Maeda, Zasso Kenkyu, 1963, 113. germination tests of rape, rice and cucumber. However, $p$-hydroxyphenylacetic acid, promoted germination of rape seeds at the concentration of $20 \mathrm{ppm}$ in water and inhibited at $250 \mathrm{ppm}$.

Acknowledgement. The authors are greatly indebted to Dr. Eijiro Hamaguchi, Emeritus Proffessor of the Hyogo University of Agriculture, for his continuous guidance. They are also grateful to Misses Mieko Hamaji and Kiyoko Nakane for microanalysis, and to Nissei Sangyo Co. for measurements of Mass spectra. The authors thank Messrs. Kenji Miyake and Ryohei Taniguchi for the technical cooperations. One of the authors (S.F.) extends his thanks to Dr. Saburo Okamoto, the Hyogo University of Agriculture, for his helpful criticism on the manuscript. 